\title{
EN-SITU EXAFS INVESTIGATION OF ZEOLITE SUPPORTED Pt ELECTROCATALYST STRUCTURE
}

\author{
$\mathrm{JUN}_{\mathrm{YAO}}{ }^{1}$ and YUFENG YAO ${ }^{2}$
}

\begin{abstract}
Experimental investigation was carried out for Pt electrochemical performance and Pt particle size using $1.5 \mathrm{wt} \%$ and $5 \mathrm{wt} \% \mathrm{Pt}$ loading on zeolite electrocatalysts made by $\mathrm{Pt}\left(\mathrm{NH}_{3}\right)_{4}\left(\mathrm{NO}_{3}\right)_{2}$ or $\operatorname{Pt}\left(\mathrm{NH}_{3}\right)_{4}\left(\mathrm{NO}_{3}\right)_{2} / \mathrm{NH}_{4} \mathrm{NO}_{3}$ salt with ion exchanged method and calcined at $350{ }^{\circ} \mathrm{C}$ and reduced at $400{ }^{\circ} \mathrm{C}$ or direct reduced at $400{ }^{\circ} \mathrm{C}$, respectively. Cycle voltammetry measurement indicated that the hydrogen energy binding level on Pt surfaces is higher for electrocatalyst under direct reduction process than those made by calcination and reduction process. Extended X-ray adsorption fine structure measurement also revealed that Pt size for electrocatalyst made by calcination and reduction method is smaller than those made by direct reduced method. Furthermore, Pt size for electrocatalysts with 1.5 $\mathrm{wt} \% \mathrm{Pt}$ loading on zeolite is smaller compared to those with $5 \mathrm{wt} \% \mathrm{Pt}$ loading electrocatalysts. Aforementioned electrochemical performance of $\mathrm{Pt}$ zeolite electrocatalysts has depicted by a hypothesis of hydrogen spillover and surface conductance pathway.
\end{abstract}

KEY WORDS: Platinum nanoparticle; Calcination and reduction; Direct reduction; Cycle voltammetry; Extended X-ray adsorption fine structure; $\mathrm{H}_{2}$ spillover and surface conductance.

\section{Introduction}

Zeolite is increasingly employed for fuel cell application due to its chemical and physical characteristics which can offer a crystallized structure with great capacity for containing water. It also can be completely hydrated and dehydrated without damage to the crystalline lattice [1]. These properties are particularly appealing to proton exchange membrane fuel cell (PEMFC) that relies on liquid water to maintain and facilitate fast electrochemical kinetics [2] during electrochemical reaction through a self-humidification process [3]. Moreover, zeolite comprising of $\left[\mathrm{SiO}_{4}\right]$ and $\left[\mathrm{AlO}_{4}\right]$ tetrahedral structure can bring extra framework of metal cations with interconnection channels to host unique chemistry features [4].

\footnotetext{
${ }^{1}$ School of Engineering, University of Lincoln, Brayford Pool, Lincoln LN6 7TS, UK, jyao@lincoln.ac.uk

${ }^{2}$ Department of Engineering Design and Mathematics, University of the West of England, Coldharbour Lane,

Bristol BS16 1QY, UK, Yufeng.Yao@uwe.ac.uk
} 
It is known that zeolite catalytic performance can be modified by pre-exchange ions to produce a desired cationic form [4]. The metal microstructure constrained within zeolite supercages varies in size from a single atom scale to nanoparticle scale in an order of $1-2 \mathrm{~nm}$ [5], forming clusters containing 10 - 25 atoms on average [6]. The metal particles supported on zeolite exteriors that are not constrained by zeolite internal architecture and their sizes can still be smaller than micrometer $[5,7]$.

Past researches have revealed that Pt is a practically important element as catalyst [8] for a variety of electrochemical reactions in acid solution, in which catalytic activity can be promoted on zeolite. A high dispersion of $\mathrm{Pt}$ on zeolite was found to be achieved by calcination and reduction steps with oxygen and hydrogen purging in the gas phase under careful temperature control. Pt was mostly located in zeolite supercages under calcination at $350{ }^{\circ} \mathrm{C}$ and reduction at $400{ }^{\circ} \mathrm{C}$ [9]. Zeolite as ionic conductor can act as an electron bank to release electrons to or absorb electrons from a reactant during an electrochemical reaction to provide an ionic conduction [10]. This will lead to an electrochemical reaction occurring in a charger balanced ionic environment like in an electrochemical system [1].

Previously, Rolison et al. $[5,11]$ have applied an approach using microelectrode by dispersing the modified zeolite powder in an electrolyte solution of high ionic strength placed between two large feeder electrodes. The complication of their methods may induce the Pt nanoparticle exchange coming out of the zeolite structure into the electrolyte solution, and thus circumventing the problem of electronic conduction within zeolite $[1,12]$.

In order to overcome those difficulties aforementioned, we are proposing to use electrode made by Y zeolite supported Pt samples mixed with XC-72R carbon powder and Nafion ${ }^{\circledR}$ as binding agent, similar to those prepared for polymer electrolyte membrane fuel cells application. Therefore, this paper will be devoted to investigate the influence of $\mathrm{Pt}$ particle size on electron transfer process by increasing the $\mathrm{Pt}$ loading from $1.5 \mathrm{wt} \%$ to $5 \mathrm{wt} \%$ on zeolite using cycle voltammetry (CV) measurement and the extended X-ray absorption fine structure (EXAFS) technique. 


\section{Experimental}

Y zeolite was used as a support for the deposition of $1.5 \mathrm{wt} \%$ or $5 \mathrm{wt} \% \mathrm{Pt}$ loadings, followed by a procedure reported previously $[13,14]$. The electrodes were prepared by dispersing a known amount of $1.5 \mathrm{wt} \%$ or $5 \mathrm{wt} \% \mathrm{Pt} / \mathrm{Y}$ zeolite samples and untreated XC-72R plain carbon powder mixed with $15 \mathrm{wt} \% \mathrm{Nafion}^{\circledR}$ on a carbon black (Vulcan XC-72R) paper hot pressed to dry out water moisture. The resultant electrode was later tested to determine Pt electrocatalytical activity by potential cycling method using potentiostat in a saturated $2.5 \mathrm{~mol} \mathrm{dm}{ }^{-3} \mathrm{H}_{2} \mathrm{SO}_{4}$ solution at a scan rate of $1 \mathrm{mV} \mathrm{s}^{-1}$ until a stable state of cyclic voltammetry (CV) obtained. An electrochemical cell employed for $\mathrm{CV}$ measurement consists of a $\mathrm{Pt} / \mathrm{Y}$ zeolite working electrode, an $\mathrm{Hg} / \mathrm{Hg}_{2} \mathrm{SO}_{4}$ Mercury/Mercuries Sulphate (MMS) reference electrode and a Pt gauze counter electrode. The electric current density was measured correspondent to an electrode disc of $2.5 \mathrm{~cm}$ diameter.

Pt particles were characterized by the en-situ extended X-ray adsorption fine structure (EXAFS) using a Synchrotron Radiation Source (SRS) at STFC Daresbury National Laboratory [13]. EXAFS data was collected using a pellet placed in a gas cell, purged with Argon (Ar). The pellet was made by the catalyst powder mixed with boron nitride to give a Pt loading of $0.73 \mathrm{mg} \mathrm{cm}^{-2}$. The resultant EXAFS data was later analyzed using software EXCURV 98.

The electrochemically assessable Pt surface areas were measured using carbon oxide (CO) adsorption and electrooxidation process, as the ratio of absorbed $\mathrm{CO}$ to $\mathrm{Pt}$ active sites was found to be unity at a full CO coverage [15]. CO absorption and stripping voltammogram was conducted in $2.5 \mathrm{~mol} \mathrm{dm}^{-3} \mathrm{H}_{2} \mathrm{SO}_{4}$ solution at ambient room temperature by bubbling $\mathrm{CO}$ for 45 minutes at $-0.55 \mathrm{~V}$. The dissolved $\mathrm{CO}$ was then stripped off on the Pt surface by purging Ar under potential cycling at a scan rate of 1 $\mathrm{mV} \mathrm{s}^{-1}$. 


\section{Results and Discussion}

\subsection{Pt surface area measurement by $\mathrm{CO}$ oxidation and stripping process}

Figure 1 depicts a $\mathrm{CV}$ comparison for $\mathrm{CO}$ adsorption and stripping peaks on the $\mathrm{Pt}$ surface using $1.5 \mathrm{wt} \%$ or $5 \mathrm{wt} \%$ Pt loading on carbon Nafion ${ }^{\circledR}$ bound electrodes made by $40 \mathrm{wt} \% \mathrm{Pt}$ on carbon with extra XR-72R carbon powder (thereafter denoted as 15PtXC-72R and 5PtXC-72R, respectively. Two CO stripping peaks were captured in a potential region of $0 \mathrm{~V}$ and $0.17 \mathrm{~V}$ for electrode $15 \mathrm{PtXC}-72 \mathrm{R}$, corresponding to a single CV stripping peak measured at $0.045 \mathrm{~V}$ for electrode 5PtXC-72R (represented by solid line). The formation of $\mathrm{Pt}$ oxide might also be involved in $\mathrm{CO}$ stripping reaction, as the oxidation of $\mathrm{CO}$ happens at a potential where the formation of $\mathrm{Pt}$ oxide occurs [16]. The two electrons are transferred in the electrooxidation of one $\mathrm{CO}$ molecule and $\mathrm{CO}$ stripping peak. The hydride region was re-emerged after $\mathrm{CO}$ stripping off on the Pt surface with a single hydrogen peak measured in hydride regions for electrode 15PtXC-72R (represented by dash lines). The hydrogen energy binding level for re-oxidation and desorption on the Pt active sites was found very similar for electrode $15 \mathrm{PtXC}-72 \mathrm{R}$. The hydride region corresponding to weakly and/or strongly hydrogen adsorption peaks, and as well as hydrogen re-oxidation and desorption peaks are clearly visible for electrode 5PtXC-72R.

Figure 2 depicts $\mathrm{CV}$ measurements for $5 \mathrm{wt} \% \mathrm{Pt}$ loading on $\mathrm{Y}$ zeolite electrodes which show a similar tendency as to that of carbon electrodes. CO stripping peaks were detected at $0.21 \mathrm{~V}$ and $0.24 \mathrm{~V}$ for electrodes 5Ptancr4 and 5Ptandr4, respectively. Multiple CO stripping peaks were also captured at $-0.24 \mathrm{~V}$ and $0.25 \mathrm{~V}$ for electrode 5Ptanxcr4. This indicated that the Pt cluster consists of multiple Pt active sites owing to different energy binding levels at which Pt active sites for catalyst 5Ptanxcr4 with excess $\mathrm{H}^{+}$ion was found low. Similar trends of hydrogen adsorption, evaluation and hydrogen desorption peaks were observed in a potential region of -0.5 $\mathrm{V}$ and $-0.65 \mathrm{~V}$ for an electrode $5 \mathrm{Ptanxcr}$. There were no visible hydrogen adsorption and desorption peaks captured for electrodes 5Ptancr4 and 5Ptandr4 after CO stripping process. 
Pt active surface areas can also be determined via hydrogen adsorption peaks. Table 1 shows a comparison of $\mathrm{Pt}$ active surface area determined by following measurements: (1) $\mathrm{CO}$ diffusion and (2) hydrogen adsorption and re-oxidation processes. Pt active surface area of catalyst $5 \mathrm{PtXC}-72 \mathrm{R}$ was predicted the largest at $28.24 \mathrm{~m}^{2} \mathrm{~g}^{-1}$, followed by catalyst 5 Ptanxcr4 at $24.29 \mathrm{~m}^{2} \mathrm{~g}^{-1}$ and catalyst 5 Ptancr4 at $20.20 \mathrm{~m}^{2} \mathrm{~g}^{-1}$, respectively. Nevertheless, the catalyst 5 Ptandr 4 made by direct reduction has shown a minimum surface area of $2.89 \mathrm{~m}^{2} \mathrm{~g}^{-1}$. Pt active surface area measured by hydrogen adsorption peaks was found higher than those predicted via $\mathrm{CO}$ adsorption peaks. The detection of increasing the $\mathrm{Pt}$ active surface area by hydrogen adsorption peaks indicated that some of Pt might be encapsulated in zeolite small cages, i.e. sodalite cage, via Pt migration through zeolite channels. In general, Pt particles in those locations are hardly accessed by $\mathrm{CO}$ diffusion for electrochemical active surface area (EASA) measurement using $\mathrm{CO}$ adsorption method, whereas $\mathrm{H}^{+}$ions enable to migrate more easily through zeolite channels. Pt active surface area of catalyst 5 Ptanxcr4 was found the highest, followed by catalyst 5Ptancr4 and 5Ptandr4, respectively. This observation indicated that Pt particle size made by hydrogen direct reduced method was larger, compared to catalysts 5 Ptanxcr4 or 5Ptancr4 under calcination and reduction method.

Figure 3 depicts $\mathrm{CV}$ measurements to determine the Pt active surface area for $1.5 \mathrm{wt} \%$ loading on zeolite via $\mathrm{CO}$ adsorption and stripping process. $\mathrm{CO}$ stripping peaks were captured at $0.18 \mathrm{~V}$ and $0.28 \mathrm{~V}$ for catalysts 15 Ptancr4 and 15Ptanxcr4, respectively. Pt active surface area for catalyst 15Ptanxcr4 (see Table 2) was measured the greatest at $96.80 \mathrm{~m}^{2} \mathrm{~g}^{-1}$, followed by $40.02 \mathrm{~m}^{2} \mathrm{~g}^{-1}$ for $15 \mathrm{Ptancr} 4$ and $35.47 \mathrm{~m}^{2} \mathrm{~g}^{1}$ for $15 \mathrm{PtXC}-$ 72R. The accessible Pt active sites determined by hydrogen adsorption peak area was found having slightly increase in surface area measured at $103.57 \mathrm{~m}^{2} \mathrm{~g}^{-1}$ for catalysts 15 Ptanxcr4 and $51.29 \mathrm{~m}^{2} \mathrm{~g}^{-1}$ for $15 \mathrm{Ptancr} 4$, respectively. The tendency of this area increase was found similar to those determined for zeolite catalysts with $5 \mathrm{wt} \% \mathrm{Pt}$ loading on zeolite. Pt active surface areas entrapped in small cages enable to be detected by hydrogen adsorption peaks, whereas it is difficult accessible via CO diffusion process.

It is clearly that the Pt deposition method has a significant effect on the performance of catalyst. Either $1.5 \mathrm{wt} \%$ or $5 \mathrm{wt} \%$ catalyst made with the excess of $\mathrm{H}^{+}$ions 
presence displays a high Pt active surface area than those made by without excess $\mathrm{H}^{+}$ ions participating. Pt active surface area given by direct reduction method is the lowest, compared to those made by calcination and reduction method. $\mathrm{CO}$ adsorption and stripping process is primarily a surface phenomenon for detection of $\mathrm{Pt}$ active sites on the exterior of zeolite. This may be contributed by $\mathrm{CO}$ molecule that is too large to diffuse through zeolite interconnection channels to access the Pt active sites encaged within zeolite structure. Therefore, it might be more accurate to measure the electrochemically active surface areas (EASAs) of Pt using hydrogen adsorption on $\mathrm{Pt}$ surface. It was found that the $\mathrm{H}^{+}$ions could spillover through zeolite active sites by the formation of $\mathrm{H}_{\mathrm{ads}}$ atom at first and then transmitting $\mathrm{H}$ species along zeolite channel to increase the surface conductance of zeolite substrate $[17,18] . \mathrm{H}^{+}$ions have been regarded as one of the most important species in this process [17]. This will result in a flow of protons along the zeolite acidic sites and transports the hydrogen species to the neighbouring $\mathrm{Pt}$ particles on zeolite. Therefore, Pt can be electrochemically accessible. Pt particle encapsulated within zeolite structure can be electrochemically reduced via hydrogen spillover process.

$1.5 \mathrm{wt} \% \mathrm{Pt}$ loading has shown high surface area distributions of Pt on zeolite in comparison to that of $5 \mathrm{wt} \%$ Pt loading on zeolite. Pt particle size might be small at low Pt loading. The increase of Pt loading can cause the sintering of Pt to produce large Pt particle size. Both the Pt particle size and structure were further investigated using the extended X-ray adsorption fine structure described below.

3.2. En-situ EXAFS measurement for $5 \mathrm{wt} \%$ Pt loading on zeolite catalyst by hydrogen chemical reduction

Pt particle size and its structure of $5 \mathrm{wt} \% \mathrm{Pt}$ loading on zeolite were further investigated by the en-situ EXAFS measurement.

Figure 4 illustrates the EXAFS Chi data and their Fourier transform fitting results. The data were collected at $\mathrm{Pt} \mathrm{L}_{\mathrm{III}}$ edge following hydrogen chemical reduction at ambient room temperature. The fitting results are presented in Table 2. For catalysts 5Ptanxcr4 and 5Ptandr4, Chi data were valid over the range of wave vectors from $2 A^{1}$ to $16.5 A^{-1}$, respectively and for 5 Ptancr4 it was only valid up to $14.5 A^{-1}$. The curve 
fitting matches raw measurement data very well. Pt coordination number in the Pt-Pt first shell for catalyst 5Ptandr4 predicated at 8.13 is found greater than those of catalysts 5Ptancr4 predicted at 7.47 and 5Ptanxcr4 at 6.02, respectively. The fitting of $\mathrm{Pt}$ shells is extended up to the Pt-Pt fourth shell for all catalysts with an averaged total of Pt atoms predicted at 19, 18 and 25 for catalysts 5Ptancr4, 5Ptanxcr4 and 5Ptandr4, respectively. A Pt-O first shell was also fitted for catalyst 5Ptanxcr4 with coordination number predicted at 0.55 and the Pt-O is fitted at $1.93 \AA$. The Pt-Pt distances are predicted at $2.76 \AA$ for catalysts 5Ptanxcr4 and 5Ptancr 4 and $2.75 \AA$ for 5Ptandr4, which are consistent to fitting results for catalysts made by $1.5 \mathrm{wt} \% \mathrm{Pt}$ loading on zeolite catalyst [13]. The present measurement data supports that Pt has metallic characteristics, which is agreed well with published results by Koningsberger et al. $[19,20]$.

The evaluated particle size is found proportional to the number of atoms in a cluster, as shown in Table 3. Pt particle for catalysts 5Ptancr4 and 5Ptandr4 consists of a total of 55 atoms in a cluster that is larger than catalysts 5Ptanxcr4 and 15Ptancr4 containing 13 atoms. The catalyst $15 \mathrm{Ptanxcr} 4$ has 12 atoms in a Pt cluster. The total surface atoms determined by Benfield method [21] are 42 for catalysts 5Ptancr 4 and 5 Ptandr4 and 12 for catalysts 15 Ptancr 4 and 15 Ptanxcr4 or 5Ptanxcr4, respectively. The average Pt particle size for $5 \mathrm{wt} \%$ Pt zeolite catalysts, i.e. 5 Ptancr 4 and 5 Ptandr4, was estimated at $1.0-2.0 \mathrm{~nm}$. Pt particle sizes for catalysts made by excess $\mathrm{H}^{+}$ions, i.e. 15 Ptanxcr4 and 5Ptanxcr4, are generally smaller than those made without excess $\mathrm{H}^{+}$ions presence, i.e. 15Ptancr4, 5Ptancr4 and 5Ptandr4. Pt particle size of catalyst 15 Ptanxcr4 estimated at $0.5-0.65 \mathrm{~nm}[13,14]$ is the smallest, compared to catalysts 15 Ptancr4 and 5Ptanxcr4 for which particle sizes were predicted at $0.8-1.0 \mathrm{~nm}$ [13, 14]. This finding demonstrates that the presence of $\mathrm{H}^{+}$ions can facilitate to achieve a high Pt distribution by anchoring Pt on zeolite specific active sites.

\subsection{Comparison}

Figure 5 depicts Pt particle distribution over Pt loading on zeolite. The catalyst 15 Ptanxcr4 made by $1.5 \mathrm{wt} \%$ Pt loading on zeolite with the excess $\mathrm{H}^{+}$ion has presented the highest Pt distribution on zeolite with the minimum Pt loading. Pt particle distribution on zeolite follows an order of 15Ptanxcr4 $>15$ Ptancr4 $>$ 
5 Ptanxcr4 $>5$ Ptancr $4>5$ Ptandr4, corresponding to a tendency of Pt loading as 15Ptanxcr4 $<15$ Ptancr $4<5$ Ptanxcr4 $<5$ Ptandr4 $<5$ Ptancr4. In general, the higher Pt distribution on zeolite can be achieved by a relatively lower Pt quantity. The excess $\mathrm{H}+$ ions can facilitate to achieve higher Pt distribution throughout zeolite channels with generally small Pt particle sizes. The catalysts, i.e. 15Ptanxcr4, 15Ptancr4 or 5Ptanxcr4, can have high mobility and transport through zeolite channels, compared to those with relatively large Pt particle size, i.e. catalysts 5Ptancr4 and 5Ptandr4. For catalyst 5Ptandr4, Pt particle is mainly located on the exterior of zeolite surface, resulting in a shell-like Pt distribution on zeolite surface.

The obtained results have demonstrated that both the Pt particle resided inside the zeolite structure as well as those located on the exterior of zeolite surface can be electrochemically accessible regardless of zeolite being an electronic insulator. In this scenario, the zeolite acts as an electron bank to release or absorb electrons during the electrochemical process. The electrocatalysts with higher Pt particle distribution of smaller sizes is shown to have a better electrochemical performance.

\section{Conclusion}

The study has shown $1.5 \mathrm{wt} \%$ and $5 \mathrm{wt} \%$ Pt loading on zeolite catalysts, prepared by $\left[\mathrm{Pt}\left(\mathrm{NH}_{3}\right)_{4}\right]^{2+} / \mathrm{NH}_{4}{ }^{+}$, are more favorably located on zeolite supercages or sodalite cages by migration through zeolite channels due to the presence of $\mathrm{H}+$ ions assisting to anchor Pt particle onto the zeolite cage walls, i.e. catalysts 15 Ptanxcr4 and 5Ptanxcr4. Pt particle for catalysts made by $\left[\mathrm{Pt}\left(\mathrm{NH}_{3}\right)_{4}\right]^{2+}$ with no excess $\mathrm{NH}_{4}{ }^{+}$ions, i.e. 5 Ptancr 4 and 5Ptandr4, are most likely located at zeolite exterior surface to form a shell-like Pt distribution on zeolite surface. Pt particle size of catalysts with excess protons is found smaller but with higher distribution on zeolite structure. This observation confirms that the electrochemical performance can be enhanced by improving $\mathrm{Pt}$ distribution on catalyst supported substrate in conjunction with the reduction of $\mathrm{Pt}$ particle size, and the electrochemical reaction can occur via surface conductance and hydrogen spillover through zeolite channels regardless of zeolite being an electronic DC insulator. 


\section{References}

1. D.R. Rolison, Zeolite-modified electrodes and electrode-modified zeolites, Chemical Review, 1990, 90(5): 867-878.

2. K. Schmidt-Rohr, Q. Chen, Parallel cylindrical water nanochannels in Nafion fuelcell membranes, Nature Material, 2008, 7: 75-83.

3. D.H. Son, R.K. Sharma, Y.G. Shul, H. Kim, Preparation of Pt/zeolite-Nafion composite membranes for self-humidifying polymer electrolyte fuel cells, J. Power Sources, 2007, 165, 733-738.

4. M.Y. Li, Industry Catalysis Principle, 1992, Tianjin University Publication (in Chinese).

5. D.R. Rolison, E.A. Hayes, W.E. Rudzinski, Electrode-modified zeolites: electrode microstructures contained in and on a heterogeneous catalyst, The Journal of Physical Chemistry, 1989, 93(14): 5524-5531.

6. B.I. Boyanov, T.I. Morrison, Support and Temperature Effects in Platinum Clusters. 1. Spatial Structure, J. Phys. Chem. 1996, 100(40):16310-16317.

7. M. Fleischmann, S. Pons, D.R. Rolison, P.P. Schmidt (eds), Ultramicroelectrodes; Datatech Science Inc. Morganton, NC. 1987.

8. N. Watari, S. Ohnishi, Electronic structure of $\mathrm{H}$ adsorbed on Pt13 clusters, J. Chemical Physics, 1997, 106(18): 7531-7540.

9. M.S. Tzou, B.K. Teo, W.M.H. Sachtler, Formation of Pt particles in Y-type zeolites: The influence of coexchanged metal cations, J. Catal., 1988, 113(1): 220235.

10. D.W. Breck, Zeolite Molecular Sieves: Structure, Chemistry and Use, 1974, John Wiley \& Sons Inc: New York.

11. D.R. Rolison, R.J. Nowak, S. Pons, J. Ghoroghchian, M. Fleischmann, In Molecular Electronic Devices III, Editor: F.L. Carter, R.E. Siatkowski, H. Wohltjen, 1988, Elsevier: Amsterdam. p401.

12. J.P. Pereira-Ramos. R. Messina, J. Perichon, Electrochemical behaviour of a silver-exchanged "mordenite"-type zeolite, J. Electroanal. Chem. and Interfacial Electrochem., 1983, 146(1): 157-169.

13. J. Yao, Y.F. Yao, Experimental study of characteristics of bimetallic Pt-Fe nano particle fuel cell electrocatalyst, Renewable Energy, 2015, 81: 182-196. 
14. J. Yao, Y.F. Yao, Investigation of zeolite supported platinum electrocatalyst for electrochemical oxidation of small organic species, International Journal of Hydrogen Energy, 2016, 41(33):14747-14767.

15. H. Igarashi, T. Fujino, M. Watanabe, Hydrogen electro-oxidation on platinum catalysts in the presence of trace carbon monoxide, J. of Electroanalytical Chemistry and Interfacial Electrochemistry, 1995, 391(1-2): 119-123.

16. K. Kunimatsu, The infrared spectrum of linearly adsorbed co species produced by chemisorption of methanol on a smooth platinum electrode at high anodic potentials, J. Electroanal. Chem. and interfacial electrochemistry, 1983, 145(1): 219-224.

17. J.M. Herrmann, P. Pichat, Evidence by Electrical Conductivity Measurements for Hydrogen Spill Over on $\mathrm{Pt}, \mathrm{Rh}$ and $\mathrm{Ni} / \mathrm{TiO} 2$ Catalysts. Consequences for Bifunctional Photocatalysis, Studies in Surface Science and Catalysis, 1983, 17: 77-87.

18. A. Zhang, I. Nakamura, K. Fujimoto, A New Probe Reaction for Studying the Hydrogen Spillover Phenomenon, J. Catalysis, 1997, 168(2):328-333.

19. D.C. Koningsberger, J.de Graaf, B.L. Mojet, D.E. Ramaker, J.T. Miller, The metal-support interaction in $\mathrm{Pt} / \mathrm{Y}$ zeolite: evidence for a shift in energy of metal $\mathrm{d}$ valence orbitals by $\mathrm{Pt}-\mathrm{H}$ shape resonance and atomic XAFS spectroscopy, Applied Catalysis A: General, 2000, 191(1-2): 205-220.

20. M. Vaarkamp, F.S. Modica, J.T. Miller, D.C. Koningsberger, Influence of Hydrogen Pretreatment on the Structure of the Metal-Support Interface in Pt/Zeolite Catalysts, J. of Catalysis, 1993, 144(2): 611-626.

21. R.E. Benfield, Mean coordination numbers and the non-metal-metal transition in clusters, J. of the Chemical Society, Faraday Transactions, 1992, 88(8):1107-1110. 

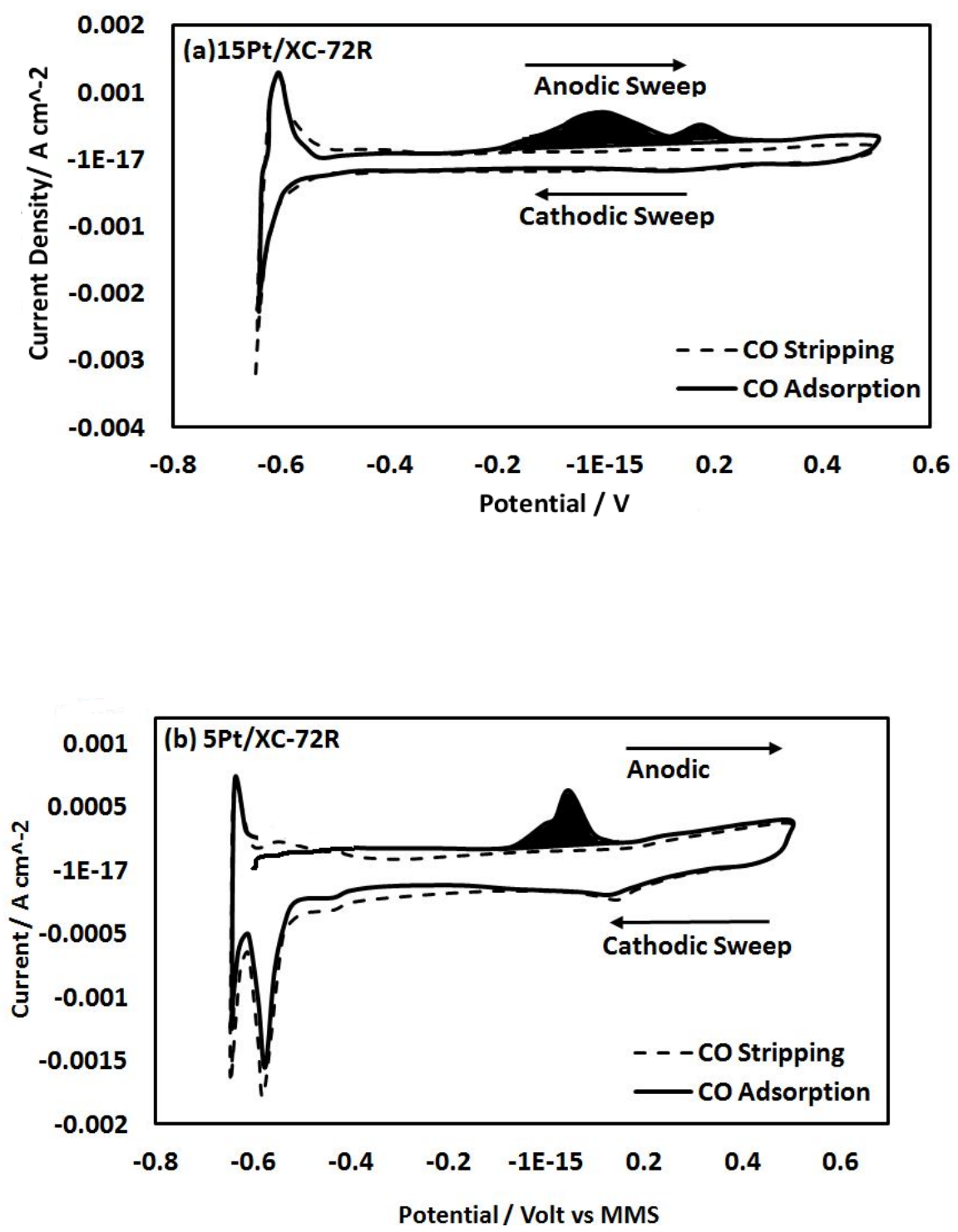

Figure 1. Steady state CV curves of CO oxidation and stripping off on the Pt surface for $1.5 \mathrm{wt} \%$ and $5 \mathrm{wt} \% \mathrm{Pt} / \mathrm{XC}-72 \mathrm{R}$ electrodes at a scan rate of $1 \mathrm{mV} \mathrm{s}^{-1}$ in $2.5 \mathrm{~mol}$ $\mathrm{dm}^{-3} \mathrm{H}_{2} \mathrm{SO}_{4}$ vs MMS reference electrode. The solid line represents CV measurement of $\mathrm{CO}$ oxidation and stripping on the Pt surface, and the dashed line represents $\mathrm{CV}$ measurement after CO stripping: (a) 15Pt/XC-72R; (b) 5PtXC-72R. 

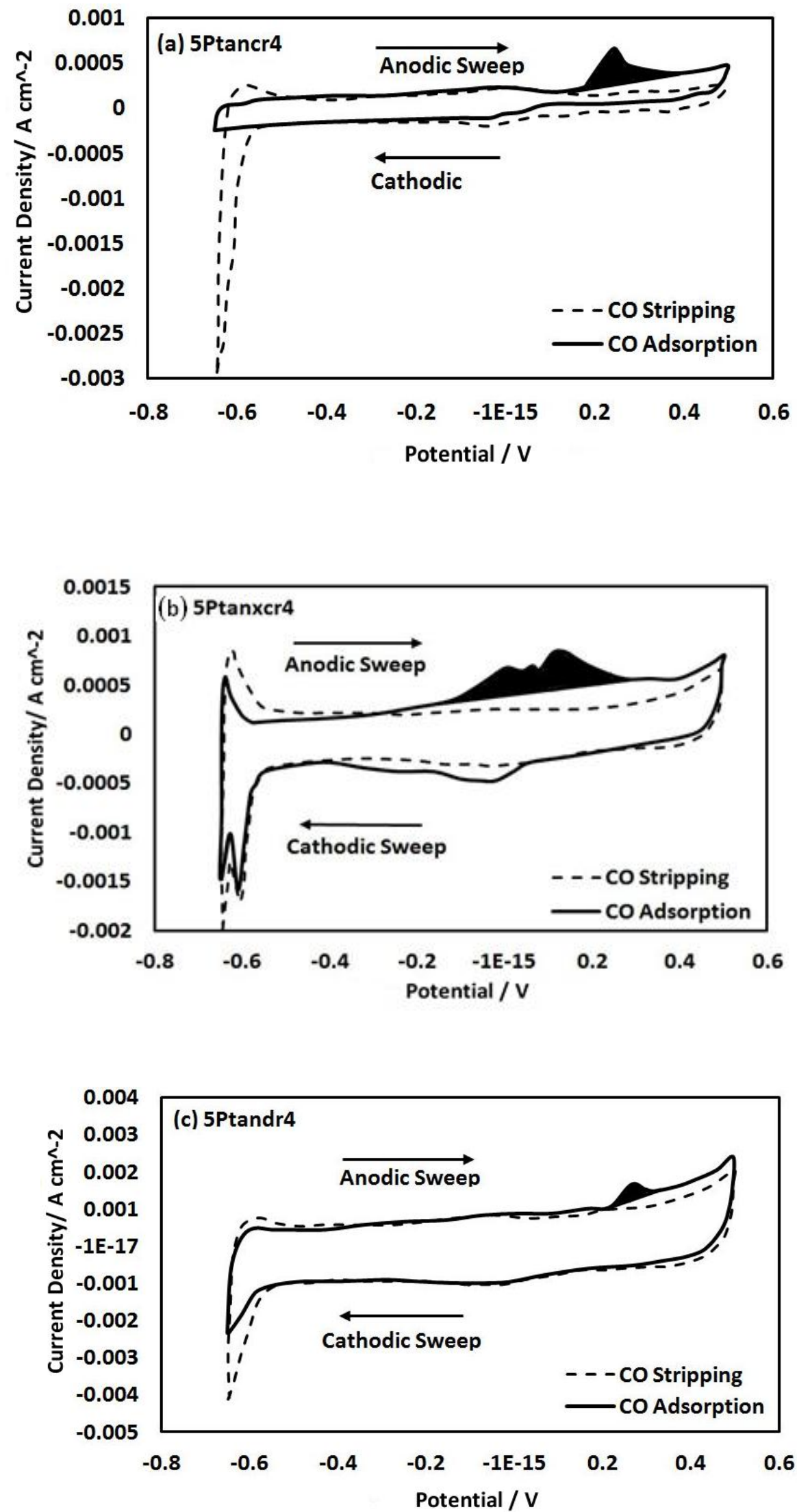
Figure 2. Steady state CV curves of CO oxidation and stripping off on the Pt surface for $5 \mathrm{wt} \%$ Pt zeolite electrodes at a scan rate of $1 \mathrm{mV} \mathrm{s}^{-1}$ in $2.5 \mathrm{~mol} \mathrm{dm}^{-3} \mathrm{H}_{2} \mathrm{SO}_{4} \mathrm{vs}$ MMS reference electrode. The solid line represents CV measurement of CO oxidation and stripping on the Pt surface, and the dashed line represents CV measurement after CO stripping: (a) 5Ptancr4; (b) 5Ptanxcr4; (c) 5Ptandr4.
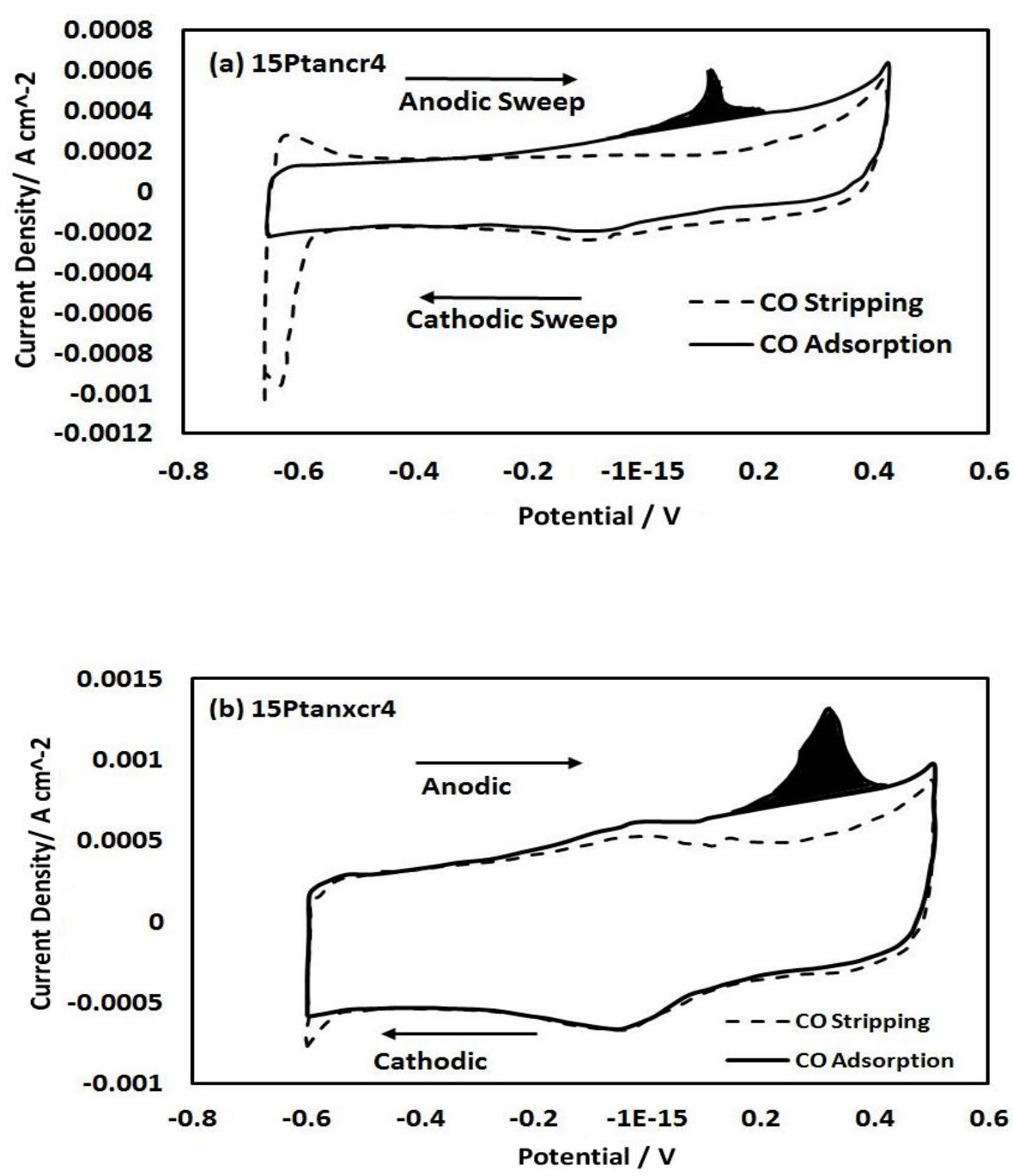

Figure 3. Steady state CV curves of CO oxidation and stripping off on the Pt surface for $1.5 \mathrm{wt} \% \mathrm{Pt}$ zeolite electrodes at a scan rate of $1 \mathrm{mV} \mathrm{s}^{-1}$ in $2.5 \mathrm{~mol} \mathrm{dm}{ }^{-3} \mathrm{H}_{2} \mathrm{SO}_{4}$ solution vs MMS reference electrode. The solid line represents CV measurement of $\mathrm{CO}$ oxidation and stripping on the Pt surface, and the dashed line represents $\mathrm{CV}$ measurement after CO stripping: (a) 15Ptancr4; (b) 15Ptanxcr4. 

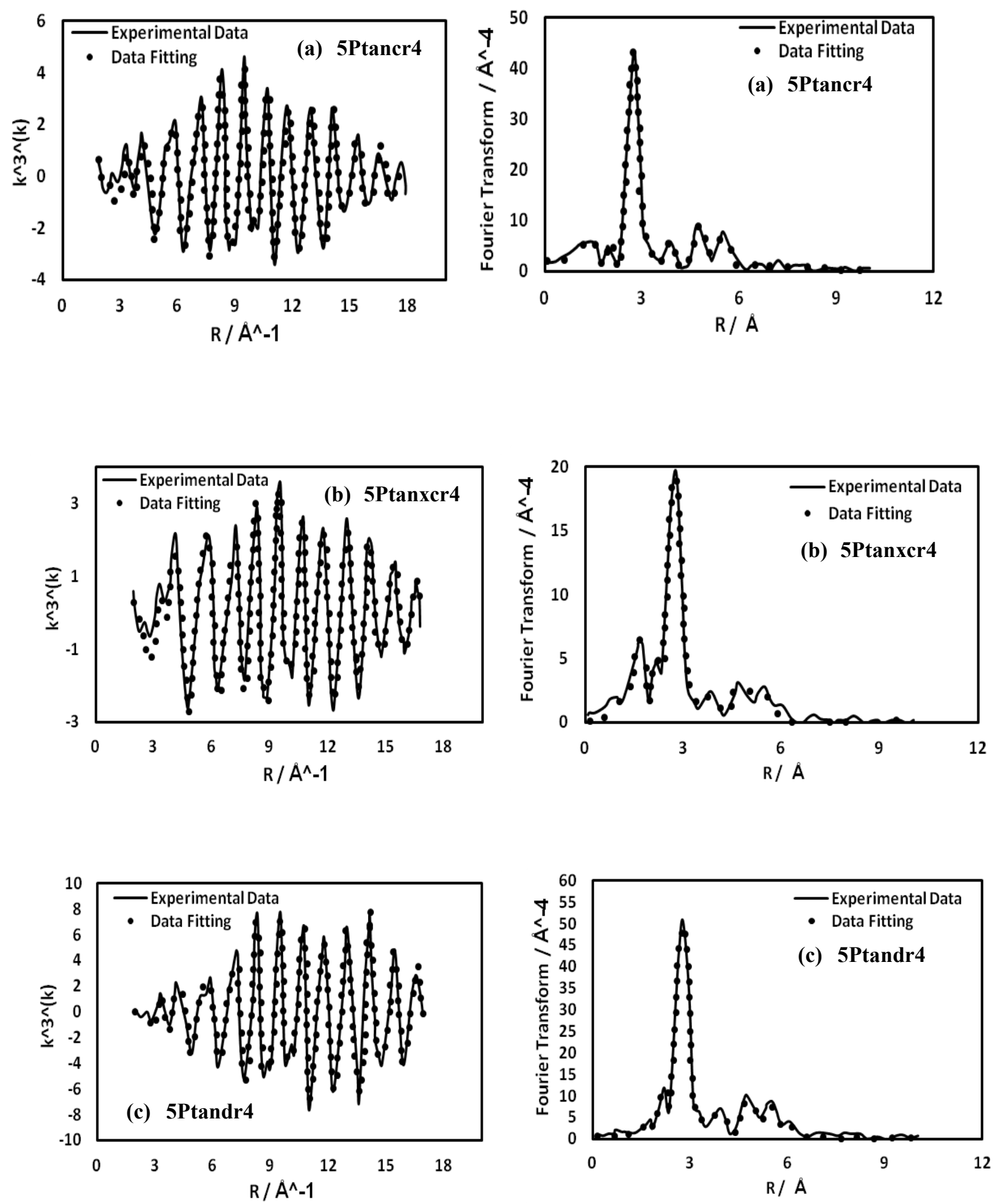

Figure 4. Chi data and Fourier transform for $5 \mathrm{wt} \% \mathrm{Pt} / \mathrm{Y}$ zeolite catalysts, phase corrected. The data were collected at $\mathrm{Pt} \mathrm{L}_{\mathrm{III}}$ edge at ambient room temperature with hydrogen chemical reduction. The solid lines are experimental data, and the dashed lines are the fitted data: (a) 5Ptancr4; (b) 5Ptanxcr4; (c) 5Ptandr4. 


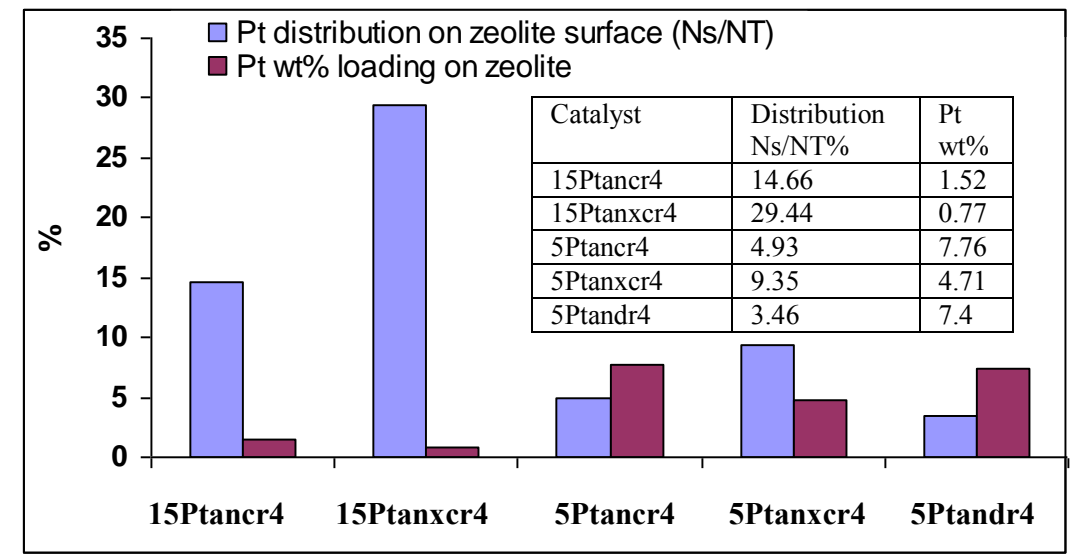

Figure 5. Comparison of $\mathrm{Pt}$ distribution and Pt loading on zeolite with catalysts made with or without excess $\mathrm{H}^{+}$ions presence under calcination and reduction or direct reduction methods, respectively. 
Table 1. Pt active surface area measurement in a potential region of $-0.65 \mathrm{~V}$ to $0.5 \mathrm{~V}$ vs MMS reference electrode.

(a) $5 \mathrm{wt} \%$ Pt loading on zeolite electrocatalyst

\begin{tabular}{|l|l|l|}
\hline Catalyst & $\begin{array}{l}\text { Pt active surface area } \\
\left(\mathrm{m}^{2} \mathrm{~g}^{-1}\right) \text { measured by } \\
\mathrm{CO}\end{array}$ & $\begin{array}{l}\text { Pt active surface area }\left(\mathrm{m}^{2} \mathrm{~g}^{-1}\right) \\
\text { measured by hydrogen } \\
\text { adsorption }[14]\end{array}$ \\
\hline 5Ptancr4 & 20.20 & 21.47 \\
\hline 5Ptanxcr4 & 24.29 & 32.61 \\
\hline 5Ptandr4 & 2.89 & 12.05 \\
\hline 5PtXC-72R & 28.24 & \\
\hline
\end{tabular}

(b) $1.5 \mathrm{wt} \% \mathrm{Pt}$ loading on zeolite electrocatalyst

\begin{tabular}{|l|l|l|}
\hline Catalyst & $\begin{array}{l}\text { Pt active surface } \\
\text { area }\left(\mathrm{m}^{2} \mathrm{~g}^{-1}\right) \\
\text { measured by CO }\end{array}$ & $\begin{array}{l}\text { Pt active surface area } \\
\left(\mathrm{m}^{2} \mathrm{~g}^{-1}\right) \text { measured by hydrogen } \\
\text { adsorption [13] }\end{array}$ \\
\hline 15 Ptancr4 & 40.02 & 51.29 \\
\hline $15 P \operatorname{Panxcr} 4$ & 96.80 & 103.57 \\
\hline 15PtXC-72R & 35.47 & \\
\hline
\end{tabular}


Table 2. EXAFS data fitting results at $\mathrm{Pt} \mathrm{L}_{\mathrm{III}}$ edge for catalysts chemically reduced by gas phase hydrogen at room temperature

(a) catalyst 5 Ptancr 4

\begin{tabular}{|c|c|c|}
\hline 5Ptancr4 & $\mathrm{N}$ & $\mathrm{R} / \AA$ \\
\hline Shell 1 Pt & $7.47 \pm 0.12$ & $2.75 \pm 0.003$ \\
\hline Shell 2 Pt & $0.47 \pm 0.16$ & $3.88 \pm 0.013$ \\
\hline Shell 3 Pt & $4.53 \pm 0.95$ & $4.79 \pm 0.015$ \\
\hline Shell 4 Pt & $6.57 \pm 1.50$ & $5.45 \pm 0.014$ \\
\hline
\end{tabular}

(b) catalyst 5 Ptanxcr4

\begin{tabular}{|c|c|c|}
\hline 5Ptanxcr4 & $\mathrm{N}$ & $\mathrm{R} / \AA$ \\
\hline Shell 1 O & $0.56 \pm 0.12$ & $1.93 \pm 0.020$ \\
\hline Shell 1 Pt & $6.02 \pm 0.14$ & $2.75 \pm 0.002$ \\
\hline Shell 2 Pt & $1.81 \pm 0.50$ & $3.89 \pm 0.015$ \\
\hline Shell 3 Pt & $4.33 \pm 0.70$ & $4.78 \pm 0.010$ \\
\hline Shell 4 Pt & $5.93 \pm 1.18$ & $5.42 \pm 0.025$ \\
\hline
\end{tabular}

(c) catalyst 5Ptandr4

\begin{tabular}{|c|c|c|}
\hline 5Ptandr4 & $\mathrm{N}$ & $\mathrm{R} / \AA$ \\
\hline Shell 1 Pt & $8.31 \pm 0.15$ & $2.76 \pm 0.001$ \\
\hline Shell 2 Pt & $3.03 \pm 0.43$ & $3.91 \pm 0.007$ \\
\hline Shell 3 Pt & $6.28 \pm 0.57$ & $4.79 \pm 0.004$ \\
\hline Shell 4 Pt & $7.49 \pm 0.98$ & $5.45 \pm 0.006$ \\
\hline
\end{tabular}


Table 3. Total Pt surface atoms and total Pt atoms in a Pt cluster

\begin{tabular}{|c|c|c|c|}
\hline $\begin{array}{c}\text { Acronym } \\
\text { Name }\end{array}$ & $\begin{array}{c}\overline{N_{1}} \text { from } \\
\text { refinement }\end{array}$ & $\begin{array}{c}\overline{N_{s}} \text { from Benfield's formula } \\
\text { (Total number of surface } \\
\text { atom in a cluster }\end{array}$ & $\begin{array}{c}\overline{N_{T}} \text { total atoms in } \\
\text { cluster }\end{array}$ \\
\hline 5 Ptancr4 & 7.47 & 42 & 55 \\
\hline 5 Ptanxcr4 & 6.02 & 12 & 55 \\
\hline 5Ptandr4 & 8.31 & 42 & 13 \\
\hline 15 Ptancr4 & 6.33 & 12 & 12 \\
\hline 15 Ptanxcr4 & 6.00 & 12 & \begin{tabular}{c}
$\mathrm{b}$ \\
\hline
\end{tabular}
\end{tabular}

${ }^{\mathrm{b}}$ Oxygen neighbors presented in the first coordination shell 